\title{
Integrating Social Media Marketing With AI through Predictive Examination
}

\author{
Gowtham Sethupathi M, Akshay U, Charan Surya M, Gohul Nath M, Sai Venkat
}

\begin{abstract}
Social Media activities have a major shift in marketing of products and have become a universal tool for advertising products. Nowadays billions of people use social media for recreational purposes and the social media activities leave a digital footprint which makes it easy to analyze each online activity. But simply having a enormous amount of data is of no use unless one can read the past and predict the future. Ai can run through data, observe patterns, give individual high quality content to each customer. The project is implemented through $U$ Methodology. This mode determines the prospect of a customer preferring a product in an online interaction through big data and predictive analysis. Involvement of artificial intelligence can reduce human error and inclination towards a certain product. The best product a customer needs is instantaneously displayed to the customer without any time lapse.
\end{abstract}

\section{Index Terms: Lapse, Methodology, Mode, Prospect}

\section{INTRODUCTION}

In the past decade whole prediction analysis concept is on the rise. It reinvents industries and plays an important role in running the modern industrialized world. As of 2017 predictive analysis drives several industries like health care, commerce, government, law enforcement. Especially in the social media sector where customer user interaction forms the central theme business model, Predictive analysis is even more important as it saves time, Reduces cost in the long run. Research comes that the Dad market can achieve seven.65 billion at interims 2020.A Gartner review furthermore checked business insight and investigation on the grounds that the much adored venture decisions for media organizations. Elite media retailers deals bunches region unit a ton of presumably to overwhelm those diverse brands inside which case the past is as of now abuse Dad as its intelligent as well .For a common man data is a dry and uninteresting pile of stuff which one couldn't be less bothered about. But this is far from the truth the fact is this pile of data is an embodiment of priceless experience of countless people using any form of online commodity from which one can learn a lot about a person's cognitive behavior. The vast, endless pile of data

Revised Manuscript Received on October 18, 2019

Gowtham Sethupathi M, Department of CSE, SRM Institute of Science and Technology, Chennai, Tamil Nadu, India.

Akshay U, Department of CSE, SRM Institute of Science and Technology, Chennai, Tamil Nadu, India.

Charan Surya M, Department of CSE, SRM Institute of Science and Technology, Chennai, Tamil Nadu, India.

Gohul Nath M, Department of CSE, SRM Institute of Science and Technology, Chennai, Tamil Nadu, India.

Sai Venkat, Department of CSE, SRM Institute of Science and Technology, Chennai, Tamil Nadu, India. enables the predictive capabilities of a machine through constant studying of patterns exhibited by a consumer in his day to day usage of the web services. The process of machines learning from this tremendous data releases the office of this detonating asset, it reveals what drives people and moves they make with the new data picked up expectation is attainable. Prophetic examination expands upon these bits of knowledge like these in order to change prophetic capacities, following assortment crunching, way and blunder technique that has its underlying foundations in information handling and designing. Right expectation is for the most part unfeasible.

The weather is analyzed with only about less accuracy, and also predicting the behavior of humans is also a daunting task, thus tool need to be developed to aid towards marketing sites which heavily rely on people to view relevant content constantly, thus the existing system needs to be upgraded in a such a manner that Ai tools takes full responsibility of the task in hand and perform the full tasks from extracting the data to full process it and present it to the user in a customized fashion.
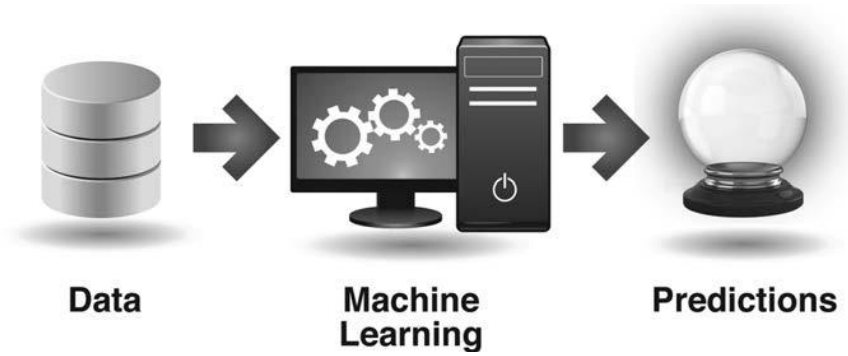

Predictions

In this way manner the tools used by Artificial intelligence helps for the user to get customized content in a fast and effective way. It is estimated that people spend around $2 \mathrm{hrs}$ a day on social media networks so by analyzing each customers daily usage of data one can find his or preferences. And one can be confident that there can be quite a few similarities between few users' data. Accordingly breaking down the examples between the couple of clients may encourage the elevating philosophy to legitimately set up the inclinations made by the client. Or maybe, the value originates from trademark a pack of individuals who-in total-will in general carry on in partner passing beyond any doubt approach.

This easily proves to us of what's about to come in the near future more accurately. Prediction through strategy work is always better than guessing, for which the result is always closer to the actual answer. Rather than having a blind eye to all the other nuances present

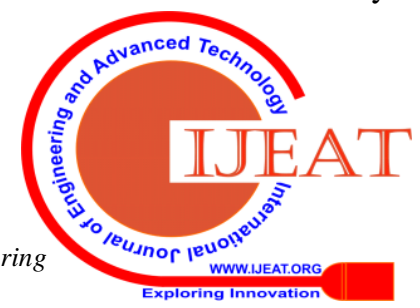




\section{Integrating Social Media Marketing With Ai through Predictive Examination}

in the problem. Thus the user's data can be used to study the user's behavioral patterns in an organized manner.

\section{EXISTING PROTOCOL}

It remains unclear why there are no steps taken to reduce to degree of human effort involved in the process of deciphering data which was done previously this involved the use of natural language prediction. The process of bit pair encoding was done to process text which contained any form of encoded words and the usual process of segmenting the data into small tokens is done to identify which word pair matches with the correct extension and the frequency of each word pair is counted. In early days the huge corpus of data would be collected though a model called RE where there are lot of hurdles to process a data. The corpus set of characters involved in this method are huge and require three common tasks which are segmenting words from running text, Normalizing word formats, Segmenting sentences in running text. The text that, this algorithm analyses must come from a specific genre of text like a telephone conversation or real life situation like scientific articles.

\section{CHALLENGES FACED BY EXISTING PROTOCOL}

Making erroneous presumptions on the fundamental instructing learning will normally result in impel the famous face. On the off chance that we will in general work with low volumes it'll result in powerless, temperamental and questionable models. Making a model that has a few branches seems to deliver higher segregation of the objective variable, anyway falls over on the grounds that it has an extreme measure of clamor. Predisposition inside the instructing learning leads as explicit customer to effectively get demonstrate.

There are several flops wherever the investigate learning has been encased inside the coaching knowledge which gives the feeling that the model goes to perform astonishingly, anyway in purpose of fact leads to a broken model. In prophetic investigation, it's sublime to pay longer on your insight approvals and obtain a second supposition to analyze the proceeding with work. Prophetic models are frequently extensively improved by making ideas to illustrate the patterns in information.

Too for the most part information researchers will work with what has been given and may not pay enough time considering further innovative decisions from the hidden data which can reinforce the models.

Machines can't fathom what the business drawback is and the route best to handle the issue. This isn't persistently uncomplicated anyway will require some cautious idea, including the all out talks with the business partners. in this manner anticipating that machines should realize the business might be a drawback.

Utilize the erroneous measurement to experience the execution of a model. Performance of the model is generally estimated exploitation wrong metric that doesn't fill any need in unmistakable misrepresentation. exploitation plain straight models on non-direct association can happen normally once, for example, building double classifiers and supply relapse is picked in light of the fact that the most well known strategy, once in purpose of actuality the association between the choices are not direct.

Utilizing tree-based models or bolster vector machines work higher in such cases. Not knowing that strategies are material to that issues leads to poor models and resulting forecasts.

Anomalies now and then legitimacy exceptional consideration or should be ignored completely Overlooking concerning exceptions can result in wasteful model. action regularization while not institutionalization can result in $\mathrm{A}$ world association solid model.

Numerous specialists aren't aware of the excess of applying regularization to the model's choices while not1st institutionalizing information| the data| the information $\}$ thus all the information is on indistinguishable scale. Regularization would be one-sided, because of it'll punish alternatives that territory unit on littler scales a ton of.

Not thinking about the timeframe assessment setting is moreover a pit fall. Specialists will regularly get occupied by structure the preeminent great model, anyway once it includes preparing, it's in this way propelled the model cannot be incorporated into the operational framework. Exploitation attributes which won't be possible inside the future, as a result of operational reasons cannot be used in demonstrating, or the catching of the circle has been suspended and will be offered inside the long hurried to be utilized inside the model.

Not thinking about this present reality suggestions and potential aftermath of applying viable prophetical investigation is one in all the chief pit fall.

\section{LITERATURE SURVEY}

\section{A. Social Computing: From Social informatics to social interactions [16]}

Social computing is a cross disciplining field which mixes social media interactions with artificial intelligence

this paper assess the potential power of ai which previously helped to just collect the data to analyze the data by identifying the several patterns. At the scaled down scale level, pro based social showing revolves around the scholarly illustrating of social lead and individual administrators' associations. The essential research issues join computational showing and social thinking about pros' feelings, helpful targets, emotions, desires, trustworthiness, social commitment, and obligations. At the vast scale level, the authority based procedure models systems including independent, instinctive masters by methods for multi-agent social generation. Reproducing complex social systems raises many research issues, for instance, show detail (for example, the central assumptions, parameters, interrelations, and rules), preliminary structure, and testing the reenactment show.

Other research troubles fuse addressing social setting, showing individual and social differentiations, and low social foundations, measures, and assembling direct ascent up out of littler scale level pro affiliations. Research openings

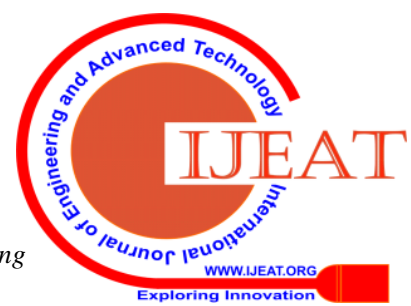


exist between individual mental showing and multi-agent social diversion. Progressing examinations have started to examine the two fields' intersection point additionally, joint effort for a prevalent perception of solitary understanding and socio-cultural methods likewise, how to consolidate mental and human sciences into handling innovations. Statistical techniques have been utilized to examine what's more, foresee the expenses and advantages related with different systems, approaches, and basic leadership methods.

\section{B. The information ecology of social media and online commodities [17]}

Online internet based life frameworks for example; online journals, wikis, media-sharing destinations, and message gatherings have turned into an essential better approach to transmit data, take part in exchanges, what's more, structure networks on the Web. Their scope and effect is huge, with a huge number of individuals giving content all the time around the world. Ongoing appraisals recommend that online life frameworks are in charge of as much as $33 \%$ of new web content. Enterprises, conventional media organizations, governments, and nongovernmental associations (NGOs) are attempting to get it the most effective method to adjust to them and use them adequately. Natives, both youthful and old, are additionally finding how online networking innovation can improve their lives and give them more voice on the planet. We should better comprehend the data nature of these new production techniques so as to make them and the data they give increasingly valuable, reliable, what's more, dependable. The blogosphere is a piece of the web and along these lines shares the vast majority of its general qualities. It varies, in any case, in manners that influence how it ought to be demonstrated, examined, what's more, abused. The normal show for the general web is as a coordinated chart of website pages with undifferentiated connects between pages. Studies on impact in informal communities and coordinated effort charts have regularly centered around the errand of distinguishing key people who play a critical job in engendering information.

\section{Narrative intelligence ${ }^{[18]}$}

Given the essential significance of account in human experience, it is nothing unexpected that story and story have for quite some time been important to artificial intelligence specialists. In the 1970's and mid 80's, there was a generous measure of enthusiasm for story comprehension and age specifically. A lovely disclosure for later scientists in rehashing these early reports is a dimension of appeal and mind in framework plan frequently lamentably ailing in contemporary research. By the by, these early account frameworks dropped out of support, experiencing a similar destiny that came to pass for some 70's artificial intelligence frameworks. They were seriously information based, which implied that they worked just in extremely restricted areas and could be made progressively broad just by an escalated and most likely in the long run infeasible learning building process. While man-made intelligence examine progressed toward becoming refocused, story turned into no less imperative. Story impacts just progressed toward becoming felt in different zones of software engineering. In these different zones, account turned into an impact as a component of a general move towards an interdisciplinary commitment with the humanities.

D. Artificial intelligence and soft computingcognitive modeling of the human brain [19]

The behaviorist perspective on discovering that illuminates quite a bit of conventional tutoring isn't prone to welcome understudies and educators to see mistakes in a positive light. Behaviorism accept that learning is improved when right reactions are remunerated positive support and off base ones are either rebuffed or doused through absence of consideration (retaining of encouraging feedback). Ways to deal with use mistakes as learning open doors may beat the conventional transmission perspective on science instructing and learning. Inside the conventional system, giving express consideration to (scientific) blunders in class is even considered by numerous individuals as unsafe since it could meddle with fixing the right outcome in the understudy's brain. To be sure, the viability of mistaken precedents for various types of students is an open issue and may depend on the individual student. Examined instructor's perspectives on these different issues have no decisive outcomes. We know just of little research in brain research which targets learning with incorrect models. Some exploration in instruction tends to learning from mistakes that others made or that are intentionally presented. For the most part, these depict positive and inventive responses of instructors to understudy mistakes in the study hall which might be difficult to actualize in a learning domain.

\section{E. Steps toward parallel intelligence [20]}

In view of the ACP approach, the parallel insight are frequently defined commonly sort of knowledge that is created from the connections and executions among physical and artificial frameworks. Parallel insight is portrayed by being information driven, exploitation SDS-based demonstrating and machine tests based framework conduct examination and investigation. The center reasoning of parallel insight for an extravagant framework is firstly, developing a parallel framework that comprises of the imperative physical frameworks and in this manner the virtual artificial frameworks. At that point, through virtual-genuine communication, the objective of parallel insight is to oversee, direct, and oversee basic leadership procedures to drive the critical framework assembly to the virtual framework.

In lightweight of the ACP approach, the parallel information are regularly defined commonly type of understanding that is made from the co tasks and executions among physical and artificial structures. Parallel information is outlined by being data driven, using SDS-based showing and machine preliminaries fundamentally based system lead examination and evaluation. the center 


\section{Integrating Social Media Marketing With Ai through Predictive Examination}

hypothesis of parallel understanding for a confounding system is firstly, building a parallel structure, that contains of the genuine physical systems and in this way the virtual artificial structures. By then, through virtual-certifiable affiliation, the objective of parallel understanding is to control, direct, and manage essential authority methods to drive the real system get together to the virtual structure.

\section{N-GRAM LANGUAGE MODEL:}

Clairvoyance is never said to be accurate. Great philosophers where stoned to death after hearing their opinions about the future. Things didn't turn to be great for a lot for a lot of people. Now we are going to discuss a lot about predicting the next character by using code and simple statistics and a lot of use of formulas. One example is "I Love Ice cream". Inside the accompanying we are getting down to business with this program by presenting models that allocate a probability for each possible word.

For what reason might we would want to anticipate imminent words? allocate probability esteems to sentences? odds are vital in errands amid which we must spot words, vague information, similar to discourse to content or hand to content . A record framework are frequently acclimated abstain from making the mistakes by exploitation the information that the succession may require that is much a ton of likely than the non-word which could be preferably increasingly moderate over what are regularly done rather than one thing that isn't related with the subject a tall.

In blunder revision, we'd like to look out and right composition framework botches like They wore lose pants, amid which free was incorrectly spelled as lose. A sentence with bottomless a great deal of reasonable and intelligent illumination is utilized, it'll be bounteous a ton of likely than one start with missteps, allowing partner degree blunder checker to detect and amend these errors.

A likelihood based model of sentences or sequential words could recommend that rapidly covers is a significantly more clear succession than brief reports or recently acquainted reports permitting us with accurately select the words which can be utilized in the sentences. Probabilities are so imperative for obscure transverse of information frameworks. The late researcher Selling UN office square measure unfit to physically talk or sign utilized this word expectation are frequently wont to advise likely words for the menu from that one will essentially pick the predetermined grouping. Models that dole out opportunities to sentences or happening words square measure alluded to as LMs.

The $\mathrm{n}$ gram sentences is divided into sequences with pairs of two words or three words or depending on the developer the various pairs can increase in size and is a sequence of letters which is used to create pairs in such a way one can use the pairs in a consecutive manner so that it may be used to make life easier.We will figure out how to utilize n-gram for the estimation of the shot of the final expression of a given past or as of late utilized words and moreover to allot an opportunity for an entire grouping. in a next to no bit of uncertain words, we tend to commonly utilize "show", and in this manner the term n-gram is either utilized word arrangement itself or the new model that doles out it a possibility.

A. Implementation Details:

\section{(i)U-Methodology}

Give us a chance to start assignment of printing $\mathrm{P}(\mathrm{z} \mathrm{d})$, the possibility of a word $z$ given the utilized history d. Expect the history $\mathrm{d}$ is " equable crossed the extension" and that we have to comprehend succeeding word is to: $\mathrm{P}$ (zebra crossed the scaffold). One approach to check this opportunity is from recurrence tallies: we tend to take an extremely goliath parcel, tally the measure of times we tend to see its equity is intersection, and tally the measure of times this is frequently trailed by two. this could be respondent the inquiry Out of the measure of times we tend to saw the history d, what rate times was it trailed by the word z", as pursues: $\mathrm{P}($ zebra crossed the bridge $)=$

C(zebra crossed the bridge to) $\mathrm{C}$ (zebra crossed the bridge)

With a curiously large enough substance, similar to the net, we will ascertain these tallies and gauge the probability from higher than condition. we will go to the net, and ascertain this gauge for yourself. The U methodology is used to convert this task into making the probability of selecting the latest feed which is most probable of coming and converting it into a format which will be used to help the AI in giving the user the same kind of product preferences which the user has selected or the users related to him have selected previously if they share a similar interest or similar connection which is most likely to be selected by the user. This is faster than the methods which is normally used and has a higher rate since it uses AI rather than humans interacting with it.

While this strategy of assessing conceivable outcomes legitimately from includes works fine in a few cases, it appears that even the online isn't adequately enormous to give US keen appraisals.

One factor we can do is disintegrate this probability abuse the chain principle of likelihood:

$\mathrm{P}(\mathrm{zd})=\mathrm{P}(\mathrm{z} 1) \mathrm{P}(\mathrm{z} 2 \mid \mathrm{z} 1) \mathrm{P}(\mathrm{z} 3 \mid \mathrm{z} 2) . . \mathrm{P}(\mathrm{zd} \mid \mathrm{zd}-1)=\mathrm{Y}$ $\mathrm{P}(\mathrm{zd} \mid \mathrm{zd}-1)$

We approximate the probability of the next letter i.e. to or with

$\mathrm{P}$ (to with) $\mathrm{P}(\mathrm{z}) \approx \mathrm{P}(\mathrm{z} \mid \mathrm{z})$

The U strategy utilizes an intriguing method to appraise likelihood which is called max enjoyed gauge or MLE. we tend to get the MLE for the parameters of partner degree n-gram display by getting checks from a customary arrangement of data, and limiting the tallies so they lie between zero and1.Using the beneath likelihood counter one can do the accompanying computations in MLE utilizing U Philosophy

$\mathrm{P}(\mathrm{zn} \mid \mathrm{zn} 1)=\mathrm{U}(\mathrm{zn}-1 \mathrm{zn})-\mathrm{U}(\mathrm{zn}-1)$

$\mathrm{U}(\mathrm{wn}-1 \mathrm{wn}) \underline{\mathrm{P}(\mathrm{wn} \mid \mathrm{wn}-1)}=\mathrm{n}-\mathrm{N}+1 \mathrm{U}(\mathrm{wn}-1-\mathrm{n} \mathrm{N}+1)$

\section{SYSTEM ARCHITECTURE}

The system architecture of the proposed system is depicted in Fig.1. The architecture is basically split into six modules which are,

- User (AI)

- Sample Dataset

- Data Storage/DBMS

- Predictive Analysis

- Apply U-Methodology

-Predicted Output 


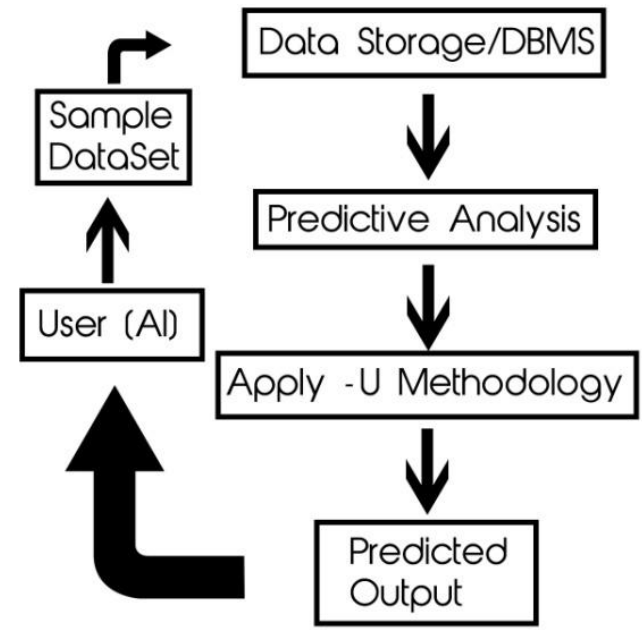

Figure 1: System Architecture

methodology can access the values and give the product preferences which are most likely to be shown as mentioned above.

\section{Results and Discussion}

$P($ feed product $) P(</ \mathrm{s}>\mid$ feed $)=.25 \times .33 \times .0011 \times 0.5 \times 0.68$ $=.000031$

Here are a few probabilities:

\begin{tabular}{|l|l|l|l|l|l|l|l|}
\hline Feed & & $\begin{array}{l}\text { Adi } \\
\text { das }\end{array}$ & $\begin{array}{l}\text { Go } \\
\text { ibibo }\end{array}$ & $\begin{array}{l}\text { Papa } \\
\text { johns }\end{array}$ & $\begin{array}{l}\text { Red } \\
\text { bus }\end{array}$ & Shoe & KFC \\
\hline Feed & 5 & 827 & 1 & 9 & 1 & 1 & 2 \\
\hline adidas & 2 & 1 & 608 & 1 & 6 & 5 & 1 \\
\hline GoIbibo & 2 & 1 & 4 & 686 & 1 & 6 & 211 \\
\hline McD & 1 & 1 & 2 & 1 & 2 & 42 & 1 \\
\hline IT & 1 & 1 & 1 & 1 & 82 & 1 & 1 \\
\hline Redbus & 15 & 1 & 15 & 1 & 4 & 1 & 1 \\
\hline Shoes & 2 & 1 & 1 & 1 & 1 & 1 & 1 \\
\hline KFC & 1 & 1 & 1 & 1 & 1 & 1 & 1 \\
\hline
\end{tabular}

trigram 4-gram 5-gram

$P(\mathrm{i} \mid<\mathrm{s}>)=0.25 P(\mathrm{KFC} \mid$ food $)=0.0011$

$P($ Redbus $\mid$ booking $)=0.5 P(</ \mathrm{s}>\mid$ feed $)=0.68$

$P(<\mathrm{s}>\mathrm{i}$ want adidas shoe

$=P(\mathrm{i} \mid<\mathrm{s}>) P($ want $\mid \mathrm{i}) P($ adidas $\mid$ want $)$

Thus using n-gram methodology, through a corpus of data from various website where marketing is clearly evident we can easily generate user related content according to the commercial choices made by the user over a period of time. This is done by obtaining user related content over period of time and determining that products one has a greater affinity. Our results are generated for 4 people who have common interest. Through the process of data collection we have identified the most common interests of these four individuals. Then the interests are segregated into four columns. Then for each of the four interests a suitable probability is generated accordingly. Then the person having the higher probability for a particular interest is identified. Then the dialect of that specific person is recognized from the huge corpus of data we have extracted from the specific time period we want to analyze the data only if the probability is greater for a specific interest for the user. Then this product is generated in the users feed also this field is generated by studying the active patterns of the specific individual i.e. the time which the user is online on a specific day. Now after we recognize the dialect of that particular individual we can feed this information in his feed so that the person of interest develops an inclination towards paying attention to the product.

In the field of social media marketing is a very important tool towards recognition of a specific product. Research indicates that $\mathrm{AI}$ involment in marketing yields $40 \%$ more at success rate in convincing the users to buying visiting the products home website. So in modern day social media sites more of the man power can be reduced in identifying these specific patterns. Another advantage of these kind of processing is that change in trends involving the rise of new products can be easily adjusted to and changed through predictive analysis. Another research indicates that customers except a detailed response from the advertiser in a few hours, So to avoid the late response time and also to give a precise response in the users own dialect. The literature also clearly showcases the basic utility of the prediction analysis methodology which was being used prior to what we have been implementing. In the survey the emphasis was to predict what the user will think in the next step, but in our model the main emphasis is to identify the product the user is about to venture in the next time one uses the product. Physiological

\begin{tabular}{|c|c|c|c|c|c|c|c|}
\hline & Feed & $\begin{array}{l}\text { Adi } \\
\text { das }\end{array}$ & $\begin{array}{l}\text { Go } \\
\text { Ibibo }\end{array}$ & $\begin{array}{l}\text { Papa } \\
\text { johns }\end{array}$ & \begin{tabular}{|l|} 
Redb \\
us \\
\end{tabular} & Shoe & KFC \\
\hline Feed & $\begin{array}{l}0.00 \\
2\end{array}$ & 0.33 & 1 & 0.0036 & 1 & 1 & $\begin{array}{l}0.0007 \\
9\end{array}$ \\
\hline Adidas & $\begin{array}{l}0.00 \\
22\end{array}$ & 1 & 0.66 & 0.0011 & $\begin{array}{l}0.006 \\
5\end{array}$ & $\begin{array}{l}0.005 \\
4\end{array}$ & 50.0011 \\
\hline $\begin{array}{l}\text { GoIbib } \\
\text { o }\end{array}$ & $\begin{array}{l}0.00 \\
08\end{array}$ & 1 & 0.0017 & 0.28 & 1 & $\begin{array}{l}0.002 \\
5 \\
\end{array}$ & 20.087 \\
\hline McD & 0 & 1 & 0.0027 & 1 & $\begin{array}{l}0.002 \\
7 \\
\end{array}$ & 0.056 & 51 \\
\hline IT & $\begin{array}{l}0.00 \\
63 \\
\end{array}$ & 1 & 1 & 1 & 0.52 & \begin{tabular}{|l}
0.006 \\
3 \\
\end{tabular} & 51 \\
\hline Redbus & $\begin{array}{l}0.01 \\
4 \\
\end{array}$ & 1 & 0.014 & 1 & $\begin{array}{l}0.003 \\
7\end{array}$ & 1 & 1 \\
\hline Shoes & $\begin{array}{l}0.00 \\
59\end{array}$ & 1 & 1 & 1 & $\begin{array}{l}0.002 \\
9\end{array}$ & 1 & 1 \\
\hline KFC & $\begin{array}{l}0.00 \\
36\end{array}$ & 1 & 0.0036 & 1 & 1 & 1 & 1 \\
\hline
\end{tabular}

researches have analyzed that making the user more involved in the product he is about to visit will result in the user more likely to purchase or share it to their friends.

This implies that our methodology of predicting the user content before one visiting the product before has serious consequences, are towards the purchase of the product. In future this method will result in the rise of over 20,000 startup products which will remain relevant through customer interaction by the process of big data and predictive analysis.

The User enters a sample data handled by AI which is actually the thing the user wanted to search. The sample data being entered by the user is stored in the data storage or the DBMS which stores data in real time that is dynamic data storage. The predictive analysis method starts predicting the upcoming word and searches 


\section{Integrating Social Media Marketing With Ai through Predictive Examination}

the database for prediction. By applying the U-Methodology the predictive analysis finds the exact search result for the user along with the suggestions and other related user preferences. The final output or the predicted output is sent back to the user by the AI and the actual predicted output is seen by the user and is used by the user for further use.

The whole concept of U-Methodology is focused on probability and predictive analysis of the next product which is mostly derived from what the user has previously selected or what the user has a high probability of selecting. This is done through a various series of combination of various data i.e. the products which are already popular and the products which are in need of sales and various other factors like that. All this is possible by using the predictive analysis used by the $\mathrm{n}$ gram methodology which plays a key part in the $\mathrm{U}$ methodology. The $U$ methodology plays a the part of

\begin{tabular}{|l|l|l|l|l|l|l|l|}
\hline feed & adidas & $\begin{array}{l}\text { Go } \\
\text { ibibo }\end{array}$ & $\begin{array}{l}\text { Mc } \\
\text { Don } \\
\text { alds }\end{array}$ & IT & Red- bus & Shoe s & KFC \\
\hline 2533 & 927 & 2417 & 746 & 15 & 1093 & 341 & 278 \\
8
\end{tabular}

formulating the data in various parts so as to give the final outcome which has a part that can be given to the user as a part of suggestion which the user is most likely to click on or select.

Now we'll need to introduce an innovative new way of assuming the probability of a word w which is the products name with a given history $h$ of the user selected related items ,or the chance of an entire sequence $\mathrm{W}$. To represent the chance of a random variable like $\mathrm{Xi}$ taking on the value "shoe", or $\mathrm{P}(\mathrm{Xi}=$ "shoe"), we will use simply $\mathrm{P}($ shoe $)$. We will now record a sequence of $\mathrm{N}$ words either as w1...wn or wn 1 (so that the expression wn-1 1 means the string $\mathrm{w} 1, \mathrm{w} 2, \ldots, \mathrm{wn}-1)$. For the chance of probability of each and every single word in a sequence flow having a exact value $P(X$ $=\mathrm{w} 1, \mathrm{Y}=\mathrm{w} 2, \mathrm{Z}=\mathrm{w} 3, \ldots, \mathrm{W}=\mathrm{wn})$ we'll use $\mathrm{P}(\mathrm{w} 1, \mathrm{w} 2, \ldots, \mathrm{wn})$. We can do the probability using the chain rule :

$\mathrm{P}(\mathrm{X} 1 \ldots \mathrm{Xn})=\mathrm{P}(\mathrm{X} 1) \mathrm{P}(\mathrm{X} 2 \mid \mathrm{X} 1) \mathrm{P}(\mathrm{X} 3 \mid \mathrm{X} 2$ 1)..P(Xn|Xn-1 1$)=$ $\mathrm{n} \mathrm{Y} \mathrm{k=}$

$\mathrm{P}(\mathrm{Xk} \mid \mathrm{Xk}-1 \mathrm{1})$

After applying the rule it turns into something like this

$\mathrm{P}(\mathrm{wn} 1)=\mathrm{P}(\mathrm{w} 1) \mathrm{P}(\mathrm{w} 2 \mid \mathrm{w} 1) \mathrm{P}(\mathrm{w} 3 \mid \mathrm{w} 21) \ldots \mathrm{P}(\mathrm{wn} \mid \mathrm{wn}-11)=$ $\mathrm{n} \mathrm{Y} \mathrm{k=}$

$1 \mathrm{P}(\mathrm{wk} \mid \mathrm{wk}-11)$

\section{Bigram Model:}

Now we have the tendency use the bigram model which approximates the chance of a word given bigram all the past words $\mathrm{P}(\mathrm{wn} \mid \mathrm{wn}-1 \quad 1$ ) by using the only conditional probability method without the chain rule of the previous word $\mathrm{P}(\mathrm{wn} \mid \mathrm{wn}-1)$. Once we use bigram model to assume the conditional probability of the upcoming or a new set of word, we are creating the subsequent approximation:

$\mathrm{P}(\mathrm{wn} \mid \mathrm{wn}-1 \quad 1) \approx \mathrm{P}(\mathrm{wn} \mid \mathrm{wn}-1)$

Now we apply the Markov's Assumption including with the $\mathrm{n}$-gram model assumptions to give a much more intricate detailed formula which increases the positive probability by much more.

Thus, the equation for this n-gram method to the conditional probability method of the upcoming word in a word sequence is

$\mathrm{P}(\mathrm{wn} \mid \mathrm{wn}-1 \quad 1) \approx \mathrm{P}(\mathrm{wn} \mid \mathrm{wn}-1 \mathrm{n}-\mathrm{N}+1)$

When we use Markov's assumption we can get to convert the word prediction which the n-gram does and take the method itself as a whole and get to mix it slightly with the bigram model so as to replace the predictive analysis to products instead of using words itself as a whole. This acts as a core for U Methodology.

When we substitute the bigram now we get the following $\mathrm{P}(\mathrm{wn} 1) \approx \mathrm{n} \mathrm{Y} \mathrm{k}=1 \mathrm{P}(\mathrm{wk} \mid \mathrm{wk}-1)$

Now we need to calculate the Maximum Likelihood Estimate i.e. MLE which plays a major role in the production of the U-Methodology. The MLE will run on the binary concept which means that the MLE will return the value in the form of $1 \mathrm{~s}$ and $0 \mathrm{~s}$. The concept that it uses is normalization. One has to convert it from machine level language to a user understandable language.

Given the bigram notation for the probability of a single data, we can calculate the chance of an entire word sequence by applying the subsequent:

$\mathrm{P}(\mathrm{wn} \mid \mathrm{wn}-1)=\mathrm{U}(\mathrm{wn}-1 \mathrm{wn}) \mathrm{PwU}(\mathrm{wn}-1 \mathrm{w})$

We use this equation to make bigram result using the above MLE equation. By using the above one gets the result in normalized form i.e. the results lie in the value of 1 and $0 . \mathrm{We}$ can simplify the equation even more by removing the ones with the low probability of being selected.

$\mathrm{P}(\mathrm{wn} \mid \mathrm{wn}-1)=\mathrm{C}(\mathrm{wn}-1 \mathrm{wn})$

$$
\mathrm{C}(\mathrm{wn}-1)
$$

For a regular case of MLE in the n-gram parameter estimation:

$\mathrm{P}(\mathrm{wn} \mid \mathrm{wn}-1 \mathrm{n}-\mathrm{N}+1)=\mathrm{U}(\mathrm{wn}-1 \mathrm{n}-\mathrm{N}+1 \mathrm{wn})$

$\mathrm{U}(\mathrm{wn}-1 \mathrm{n}-\mathrm{N}+1$ The above code is the estimation combination of both MLE and n-gram and bigram . The above equation helps us to get the data in binary form which is then converted into a format that uses the data and gives the result in such a which gives the data in a format which gives the prediction as a output in the form of binary conduct. The tag $\langle\mathrm{u}\rangle\langle/ \mathrm{u}\rangle$ is used whenever one has to apply the query to the data. One of the data to be given as prediction will be in the format of the following example.

$\mathrm{P}(<\mathrm{s}>$ shoe $</ \mathrm{s}>)=\mathrm{P}(\mathrm{i} \mid<\mathrm{s}>) \mathrm{P}($ adidas $\mid \mathrm{P}($ nike $) \mathrm{P}($ shoe $\mid$ vans $)$

$\mathrm{P}(</ \mathrm{s}>\mid$ shoe $)=.25 \times .33 \times .0011 \times 0.5 \times 0.68=.000031$

But one of the disadvantage is that not always does the method provide a whole numbered result . It mostly provides the data in the format of decimal values which is then compared and calculated using logarithms.

$\mathrm{p} 1 \times \mathrm{p} 2 \times \mathrm{p} 3 \times \mathrm{p} 4=\exp (\log \mathrm{p} 1+\log \mathrm{p} 2+\log \mathrm{p} 3+\log \mathrm{p} 4$

This is then converted using log methods since the values are very minute so the 


\section{CONCLUSION AND FUTURE WORK}

Thus this methodology could prove decisive in online marketing in the near future. Marketing corporation giants want their products to reach as many people as much as possible in delivering them the right commodity. However the biggest obstacle in this method is to find the right consumer who might be instantly pulled towards the product. Assigning humans towards this task costs a lot of human resources and precious time. To overcome this problem one can assign an ai which can operate for a large number of customers simultaneously in observing their data and developing a likelihood for them to use or prefer a product in the future .Once this process is done with the corporations can easily sell their products and increase their profit ratio. This process can be fully made automatic in the near future with the help of ai and this powerful methodology. This will reduce marketing cost done by other sources such as television and also increase profit percentage and boost company revenue in a short span of time.

\section{REFERENCES}

1. L. SCHWARTZ, "MEMORY FOR PEOPLE: INTEGRATION OF FACE, VOICE, NAME,

2. And biographical information," in The SAGE Handbook of Applied Memory, vol. 1. London, U.K.: SAGE, 2013, pp. 3-

3. Herrmann, J. Call, M. V.Hernandez-Lloreda,Hare, and

4. M. Tomasello, "Humans have evolved specialized skills of social cognition: The cultural intelligence hypothesis," Science, vol. 317, no.5843, pp. 1360-1366, 2007

5. D. Goleman, Social Intelligence: The New Science of Human Relationships. New York, NY, USA: Bantam Dell, 2006.

6. M. Burton and V. Bruce, "I recognize your face but I can't remember your name: A simple explanation?" Brit. J. Psychol., vol. 83, no. 1, pp. 45-60, 1992.Koleand A. F. Healy, "Memory for details about people: Familiarity, relatedness, and gender congruency, "Memory Cogn., vol. 39, no. 4, pp. 637-648, 2011.

7. M. L. Meyer, "Social working memory:

8. Neuro cognitive networks and plasticity," Ph.D. dissertation, Dept. Psychol., Univ. California, at Los Angeles, Los Angeles, CA, USA, 2014.

9. D. Baddeley, "Working memory: Looking back and looking forward," Nat. Rev. Neurosci., vol. 4, no. 10, pp. 829-839,2003.

10. Thornton and A. R. A. Conway, "Working memory for social information: Chunking or domain-specific buffer," NeuroImage, vol. 70, pp. 233-239, Apr. 2013.

11. T. L. Griffiths, C. Kemp, and J. B. Tenenbaum, "Bayesian models of cognition," in The Cambridge Handbook of Computational Psychology, R. Sun, Ed. Cambridge, U.K.: Cambridge Univ.Press,2008.

12. J. Surowiecki, The Wisdom of Crowds: Why the Many Are Smarter Than the Few and How Collective Wisdom Shapes Business, Economies, Societies, and Nations. New York, NY, USA: Random House, 2004.

13. M. D. Lee, M. Steyvers, M. De Young, and B. Miller, "Inferring expertise in knowledge and prediction ranking tasks," Topics Cogn.Sci., vol. 4, no. 1, pp. $151-163,2012$.

14. M. L. Meyer and M. D. Lieberman, "Social working memory: Neurocognitive networks and directions for future research," Front Psychol., vol. 3, no. 12, pp. 1-11, 2012.

15. J. S. Beer and K. N. Ochsner, "Social cognition: A multi level analysis," Brain Res., vol. 1079, no. 1, pp. 98-105, 2006.

16. Xu et al., "Exploring users' attitudes towards social interaction assistance on Google Glass," in Proc. 6th ACM Int. Conf. Augmented Human, Singapore, 2015, pp. 9-12.

17. J. J. Skowronski, R. J. McCarthy, and B. M. Wells, "Person memory: Past, perspectives, and prospects," in The Oxford Handbook of Social Cognition, D. E. Carlston, Ed. New York, NY, USA: Oxford Univ.Press, 2013.

18. Social computing from social informatics to social intelligence Fei Yue Wang, Daniel Zeng)

19. The Information ecology of Social Media and Online Commodities

20. Narrative Intelligence [Micheal Meteas, Phoebe Sengers]

21. Artificial Intelligence and soft computing-computing

22. Cognitive Modelling of the Human Brain [ Amit Komar]

23. Steps Toward parallel Intelligence [Fei Yue Wang, Xio Wang Li, Li]

\section{Authors Profile}

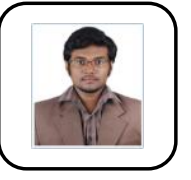

Gowtham Sethupathi M, Received M.E. degree from Anna University in the year 2015. His research interests include Natural Language Processing. He is an Assistant Professor (O.G) for the Department of Computer Science and Engineering, SRM Institute of Science and Technology. Ramapuram Campus.

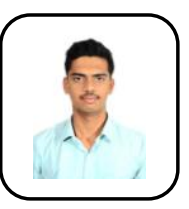

Akshay U, pursuing B. Tech degree in the department of Computer Science and Engineering, Ramapuram Campus, graduating in the year 2019. His research interests include Data Analyzing and development.

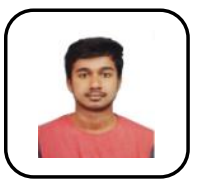

Charan Surya M, pursuing B. Tech degree in the department of Computer Science and Engineering, Ramapuram Campus, graduating in the year 2019. His research interests include Internet of Things, Artificial Intelligence and Product development.

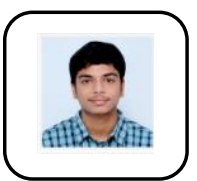

Gohul Nath M, pursuing B. Tech degree in the department of Computer Science and Engineering, Ramapuram Campus, graduating in the year 2019. His research interests include Artificial Intelligence, Data Analysis and Algorithms.

Sai Venkat, pursuing B. Tech degree in the department of Computer Science and Engineering, Ramapuram Campus, graduating in the year 2019. His research interests include Data Mining, Big data, embedded systems and other all aspects of programming 